\title{
Herbal Medicines for Irinotecan-Induced Diarrhea
}

\author{
Liu Tang, Xiaolei Li, Liping Wan, Yao Xiao, Xin Zeng and Hong Ding*
}

Key Laboratory of Combinatorial Biosynthesis and Drug Discovery, Ministry of Education, School of Pharmaceutical Sciences, Wuhan University, Wuhan, China

Irinotecan (CPT-11), a water-soluble derivative of camptothecin, belongs to the class of DNA topoisomerase I inhibitors and has been approved worldwide for the treatment of advanced colorectal cancer, lung cancer, and malignant lymphoma. Although CPT11-based chemotherapy is widely used, severe gastrointestinal (Gl) toxicity, especially late-onset diarrhea, is a common adverse reaction, limiting clinical application of the drug. The incidence of grade 3 or 4 diarrhea is high, with $20-40 \%$ of CPT-11-treated patients experiencing this adverse effect. High-dose loperamide and octreotide are generally recommended for treatment of CPT-11-induced diarrhea. However, in clinical practice, loperamide is associated with a significant failure rate and the beneficial effects of octreotide are controversial. An accumulating number of recent studies have suggested that medicinal herbs and their derived phytocompounds may be effective complementary treatments for CPT-11-induced diarrhea. In this mini-review, we

OPEN ACCESS

Edited by:

Min Ye,

Peking University, China

Reviewed by:

Shuai Ji,

Xuzhou Medical University, China

Wei Song,

Peking Union Medical College

Hospital (CAMS), China

*Correspondence:

Hong Ding

dinghong1106@whu.edu.cn

Specialty section: This article was submitted to

Ethnopharmacology,

a section of the journal

Frontiers in Pharmacology

Received: 09 December 2018

Accepted: 13 February 2019

Published: 29 March 2019

Citation:

Tang L, Li X, Wan L, Xiao Y, Zeng $X$ and Ding H (2019) Herbal Medicines for Irinotecan-Induced Diarrhea. Front. Pharmacol. 10:182.

doi: 10.3389/fphar.2019.00182 briefly summarize currently available literatures regarding the formulae and herbs/natural products used as adjuvants in animal and clinical studies for the treatment of diarrhea caused by CPT-11.

Keywords: chemotherapy-induced diarrhea, irinotecan, herbal formulations, phytochemicals, mini-review

\section{INTRODUCTION}

Diarrhea is one of the most common and dose-limiting toxicities associated with a variety of chemotherapeutic agents, including fluorouracil (FU), capecitabine, and CPT-11, which are used to treat cancer. These chemotherapeutic agents induce diarrhea in $50-80 \%$ of patients when used alone or in combination (Benson et al., 2004; Sharma et al., 2005; Stein et al., 2010). Chemotherapyinduced diarrhea (CID), even low grade (1 or 2), remarkably interferes with anticancer treatment, leading to treatment delays (28-71\% of patients), dose reductions $(22-45 \%$ of patients), or complete treatment discontinuation (3-15\% of patients) (Arbuckle et al., 2000; Arnold et al., 2005; Dranitsaris et al., 2005; McQuade et al., 2016). Severe CID (grade 3 or 4) causes significant dehydration, electrolyte imbalance, and nutritional deficiencies, which are linked to early death in roughly $5 \%$ of patients (Rothenberg et al., 2001; Andreyev et al., 2014).

CPT-11 is an established and highly effective chemotherapeutic agent used for the treatment of colon, colorectal, lung, pancreatic, as well as other types of cancer (Rosen, 1998; Mukai et al., 2009; Hayashi et al., 2013; Satouchi et al., 2014). However, severe and unpredictable doselimiting toxicities, such as neutropenia, myelosuppression, and GI toxicity, represent a significant barrier to clinical use (Kakolyris et al., 2001; Benson et al., 2004). Persistent and severe CPT-11associated diarrhea is debilitating and can be life-threatening. Notably, octreotide and high-dose loperamide, recommended to relieve severe late-onset diarrhea, are non-specific and often produce unsatisfactory results (Barbounis et al., 2001; Benson et al., 2004; Hoff et al., 2014). There is a great 
interest in finding more effective modulating agents that either alleviate delayed-onset diarrhea induced by CPT-11 chemotherapy and/or enhance antitumor efficacy.

Herbal medicines are currently of great interest to physicians because of their potential to minimize side effects of cancer treatments and improve patients' quality-of-life (QOL). Botanicals have been widely used in the United States, Japan, Korea, and China, either as mono-therapies or as adjuvants to existing conventional therapeutics (Yamashita et al., 2002; Hori et al., 2008; Park et al., 2012; Rashrash et al., 2017). In recent years, several herbal medicines and phytochemicals have been investigated in animal models and clinical trials to assess their effects on CPT-11-induced diarrhea. This mini-review focuses on the use of medicinal herbs and their bioactive constituents for the treatment or prevention of CPT11-induced diarrhea and their underlying biochemical and cellular mechanisms.

\section{CPT-11 ASSOCIATED DIARRHEA}

The biochemical mechanisms for CID are not fully understood, but are believed to involve inflammation, secretory dysfunction, and GI dysmotility (McQuade et al., 2016). CPT-11-induced GI toxicity differs from that of other antitumor regimens in that it causes early-onset (onset $\leq 24 \mathrm{~h}$ after administration) and lateonset diarrhea (onset $>24 \mathrm{~h}$ after administration) (Richardson and Dobish, 2007).

The underlying pathogenesis for early-onset diarrhea most likely involves inhibition of acetylcholinesterase activity. Earlyonset diarrhea can be ameliorated or prevented by prophylactic or therapeutic intravenous or subcutaneous administration of $0.25 \mathrm{mg}$ to $1 \mathrm{mg}$ of atropine (Gandia et al., 1993; Bleiberg and Cvitkovic, 1996; Yang et al., 2005). One proposed mechanism for CPT-11-induced late-onset diarrhea is intestinal exposure to SN-38 (7-ethyl-10-hydroxycamptothecin), the major active metabolite of CPT-11, resulting in colonic and intestinal mucosal damage (Hecht, 1998). Based on in vivo CPT-11 metabolic pathways (Stein et al., 2010; Swami et al., 2013), SN-38induced diarrhea is influenced by carboxylesterase (Ahmed et al., 1999), bacterial $\beta$-glucuronidase (Kehrer et al., 2001), and UDP-glucuronosyltransferase (UGT) (Smith et al., 2006), all of which lead to accumulation of the toxic metabolite SN38 in the intestines. CPT-11 and SN-38 may also stimulate production of prostaglandins (PGs) in the rat colon (Kase et al., 1998; Yang et al., 2005), which play a key role in water and electrolyte balance, and production of proinflammatory cytokines, such as TNF- $\alpha$, IL-1 $\beta$, and IL-6 in intestinal tissue (Richardson and Dobish, 2007; Logan et al., 2008; Melo et al., 2008).

\section{CURRENT TREATMENTS FOR CPT-11-INDUCED DIARRHEA AND LIMITATIONS}

To diagnose and determine the severity of CID, the National Cancer Institute Common Toxicity Criteria are an internationally recognized set of guidelines that assess symptoms on a scale of $0-5$ (0 representing no toxicity; 5 indicating death). Standard guidelines for evaluation and management of CID were published in 2004 and updated in 2014 (Benson et al., 2004; Andreyev et al., 2014).

Generally, CPT-11-induced diarrhea can be managed by dietary modification and administration of standard antidiarrheal medications such as loperamide, the somatostatin analog octreotide, and deodorized tincture of opium. Major chemotherapeutic agents and potential underlying mechanisms for treatment of CPT-11-induced diarrhea are summarized in Table 1. However, clinical studies have demonstrated that current therapies often contribute to worsening of existing chronic gastrointestinal symptoms or induce other side effects including respiratory depression, uneven heartbeat, seizures, and neurotoxicity (Takasuna et al., 1995a; Swami et al., 2013; McQuade et al., 2016).

\section{HERBAL MEDICINES FOR TREATMENT AND PREVENTION OF CPT-11-INDUCED DIARRHEA}

As current therapies for CPT-11-induced diarrhea are nonspecific and exhibit limited efficacy, discovery of more effective modulator agents that relieve toxic side effects associated with CPT-11 treatment is essential.

Several emerging and existing therapies such as herbal formulas, plant extractions, and phytochemicals have been proven effective for the treatment and prevention of CPT11-related diarrhea in preclinical and clinical studies. The chemical components of herbal formulas usually act simultaneously and synergistically on multiple targets in the body, representing valuable sources for the development of multi-compound and multi-target therapies to control GI toxicity (Tang and Eisenbrand, 1992; Wang et al., 2012; Swami et al., 2013).

\section{Huangqin Decoction}

Huangqin decoction (HQD), a traditional Chinese medicine, consists of four medicinal herbs, including Scutellaria baicalensis Georgi, Glycyrrhiza uralensis Fisch, Paeonia lactiflora Pall, and Ziziphus jujuba Mill at ratio of 3:2:2:2 by dry weight (Table 2). HQD has been widely used in China for over 1800 years to treat GI syndromes that are accompanied with symptoms such as diarrhea, nausea, abdominal cramps, and vomiting (Bensky and Barolet, 1990; Wang et al., 2015). In animal experiments, co-administration with HQD (10 g/kg; b.i.d.) significantly ameliorated CPT-11-induced late-onset diarrhea in rats, but failed to prevent acute diarrhea occurring on days 1 and 2. Researchers applied a GC/MS and LC/MS metabolomics approach to detect serum metabolite changes in male SpragueDawley rats with or without HQD treatment and put forward that HQD mediated metabolic alterations through reversal of amino acid, lipid, and bile acid metabolic pathways (Cui et al., 2017; Wang et al., 2017). Moreover, Cui et al. (2017) demonstrated that $S$. baicalensis played a crucial role in the therapeutic effects of HQD on CPT-11-induced diarrhea. 
TABLE 1 | Major chemotherapeutic agents for the treatment of CPT-11-induced diarrhea.

\begin{tabular}{|c|c|c|c|c|}
\hline $\begin{array}{l}\text { Chemotherapeutic } \\
\text { agent }\end{array}$ & Mechanisms of action & Optimal dose & Side effects & Reference \\
\hline Loperamide & $\begin{array}{l}\text { Acts at } \mu \text {-opioid receptor; } \\
\text { slows intestinal peristalsis; } \\
\text { anti-secretory effects through } \\
\text { inhibition of TXA2 }\end{array}$ & $\begin{array}{l}4 \mathrm{mg} \text { initial dose followed by } \\
2 \mathrm{mg} \text { every } 2-4 \mathrm{~h}\end{array}$ & $\begin{array}{l}\text { Constipation, flatulence, headache, } \\
\text { nausea, dizziness, abdominal pain, } \\
\text { worsening of already present } \\
\text { bloating, nausea and vomiting, } \\
\text { increasing incidents of paralytic ileus }\end{array}$ & $\begin{array}{l}\text { Abigerges et al., 1994; Benson et al., } \\
\text { 2004; Sharma et al., 2005; Richardson } \\
\text { and Dobish, 2007; Stein et al., } 2010\end{array}$ \\
\hline Octreotide & $\begin{array}{l}\text { Reduces the secretion of } \\
\text { specific gut hormones; } \\
\text { prolongates intestinal transit } \\
\text { time; promotes intestinal } \\
\text { absorption of fluids and } \\
\text { electrolytes }\end{array}$ & $\begin{array}{l}\text { Persistent diarrhea (grade } 1 \text { or } \\
\text { 2) and severe diarrhea (grade } 3 \\
\text { or 4): } 100-150 \mu \mathrm{g} \text { via } \\
\text { subcutaneous injection, t.i.d. } \\
\text { with dose escalation up to } \\
500 \mu \mathrm{g} \text {, t.i.d. }\end{array}$ & $\begin{array}{l}\text { Fast, slow, or irregular heartbeat, } \\
\text { constipation, abdominal or stomach } \\
\text { pain, nausea and vomiting, headache } \\
\text { and dizziness }\end{array}$ & $\begin{array}{l}\text { Gebbia et al., 1993; Barbounis et al., } \\
\text { 2001; McQuade et al., } 2016\end{array}$ \\
\hline $\begin{array}{l}\text { Deodorized tincture } \\
\text { of opium }\end{array}$ & $\begin{array}{l}\text { Inhibits intestinal peristalsis; } \\
\text { increases intestinal transit time; } \\
\text { promotes fluid reabsorption }\end{array}$ & $\begin{array}{l}10-15 \text { drops in water every } \\
3-4 \mathrm{~h}\end{array}$ & $\begin{array}{l}\text { Constipation, nausea, vomiting, } \\
\text { dizziness, drowsiness, itching, hives } \\
\text { or welts, seizures, psychological and } \\
\text { physical dependence, respiratory } \\
\text { depression }\end{array}$ & $\begin{array}{l}\text { Benson et al., 2004; Richardson and } \\
\text { Dobish, 2007; Benyamin et al., 2008; } \\
\text { McQuade et al., } 2016\end{array}$ \\
\hline
\end{tabular}

TABLE 2 | Summary of the proved effects of herbal medicines in CPT-11-induced diarrhea.

\begin{tabular}{|c|c|c|c|c|}
\hline Name of formula & Botanical latin name & Ratio & Mechanisms of action & References \\
\hline $\begin{array}{l}\text { Huangqin } \\
\text { decoction }\end{array}$ & $\begin{array}{l}\text { Scutellaria baicalensis Georgi, Glycyrrhiza } \\
\text { uralensis Fisch, Paeonia lactiflora Pall, Ziziphus } \\
\text { jujuba Mill }\end{array}$ & $3: 2: 2: 2$ & $\begin{array}{l}\text { Alters amino acids (glutamine, } \\
\text { tryptophan, glycine, serine, and } \\
\text { threonine), lipids, and bile acids } \\
\text { metabolisms }\end{array}$ & $\begin{array}{l}\text { Wang et al., 2015, 2017; Cui } \\
\text { et al., } 2017\end{array}$ \\
\hline PHY906 & $\begin{array}{l}\text { Scutellaria baicalensis Georgi, Glycyrrhiza } \\
\text { uralensis Fisch, Paeonia lactiflora Pall, Ziziphus } \\
\text { jujuba Mill }\end{array}$ & Unknown & $\begin{array}{l}\text { Promotes regeneration of intestinal } \\
\text { progenitor or stem cells and several } \\
\text { Wnt signaling components; attenuates } \\
\text { intestinal inflammation }\end{array}$ & $\begin{array}{l}\text { Lam et al., 2010; Swami et al., } \\
2013\end{array}$ \\
\hline Hange-shashin-to & $\begin{array}{l}\text { Pinellia ternate Breit, Scutellaria baicalensis } \\
\text { Georgi, Glycyrrhiza uralensis Fisch, Ziziphus } \\
\text { jujuba Mill, Panax ginseng C.A. Mey, Coptis } \\
\text { chinensis Franch, Zingiber officinale Rosc }\end{array}$ & $\begin{array}{l}5: 2.5: 2.5: 2.5: 2.5: \\
1.0: 2.5\end{array}$ & $\begin{array}{l}\text { Inhibits } \beta \text {-glucuronidase; decreases } \\
\text { colonic prostaglandin E2 production; } \\
\text { increases water absorption }\end{array}$ & $\begin{array}{l}\text { Yokoi et al., 1995; Kase et al., } \\
\text { 1997a; Swami et al., 2013; } \\
\text { Yamakawa et al., } 2013\end{array}$ \\
\hline Sairei-to & $\begin{array}{l}\text { Radix Bupleuri Chinensis, Pinellia ternate Breit, } \\
\text { Alisma orientalis (Sam.) Juzep, Scutellaria } \\
\text { baicalensis Georgi, Panax ginseng C. A. Mey, } \\
\text { Ziziphus jujuba Mill, Poria cocos (Schw.) Wolf, } \\
\text { Polyporus umbellatus (Pers.) Fries, Rhizoma } \\
\text { Areactylodis Lanceae, Cinnamomum cassia } \\
\text { Presl, Glycyrrhiza uralensis Fisch, Zingiber } \\
\text { officinale Rosc }\end{array}$ & $\begin{array}{l}7: 5: 5: 3: 3: 3: 3: 3: \\
3: 2: 2: 1\end{array}$ & Inhibits $\beta$-glucuronidase & $\begin{array}{l}\text { Takasuna et al., 1995b; Satoh } \\
\text { et al., } 2018\end{array}$ \\
\hline $\begin{array}{l}\text { Shengjiang Xiexin } \\
\text { decoction }\end{array}$ & $\begin{array}{l}\text { Pinellia ternate Breit, Glycyrrhiza uralensis Fisch, } \\
\text { Coptis chinensis Franch, Ziziphus jujuba Mill, } \\
\text { Zingiber officinale Rosc, Scutellaria baicalensis } \\
\text { Georgi, Codonopsis pilosula (Franch.) Nannf, } \\
\text { Zingiberis Rhizoma Recens }\end{array}$ & 9:9:3:12:3:9:9:12 & $\begin{array}{l}\text { Inhibits intestinal apoptosis and } \\
\beta \text {-glucuronidase; promotes intestinal } \\
\text { cell proliferation }\end{array}$ & $\begin{array}{l}\text { Deng et al., 2017; Guan et al., } \\
2017 \text { a }\end{array}$ \\
\hline $\begin{array}{l}\text { Banxia Xiexin } \\
\text { decoction }\end{array}$ & $\begin{array}{l}\text { Pinellia ternata Breit, Scutellaria baicalensis } \\
\text { Georgi, Zingiber officinale Rosc, Salvia } \\
\text { miltiorrhiza Bunge, Glycyrrhiza uralensis Fisch, } \\
\text { Coptis chinensis Franch, Ziziphus jujuba Mill }\end{array}$ & $12: 9: 9: 9: 9: 3: 16$ & Unknown & $\begin{array}{l}\text { Wang Y. et al., 2014, Chen } \\
\text { et al., } 2015\end{array}$ \\
\hline St. John's wort & Hypericum perforatum & - & $\begin{array}{l}\text { Alters CPT- } 11 \text { and SN-38 } \\
\text { pharmacokinetics; inhibits } \\
\text { pro-inflammatory cytokines and } \\
\text { intestinal epithelial apoptosis }\end{array}$ & Hu et al., 2005, 2006, 2007 \\
\hline
\end{tabular}

\section{PHY906}

PHY906, a modified four-herb pharmaceutical preparation derived from a traditional Chinese medicine formulation of HQD, was shown to be a modulator of chemotherapeutic agents in cancer therapy (Lam et al., 2010). Liu and Cheng (2012) from
Professor Yung-Chi Cheng's Team at the Yale University School of Medicine and PhytoCeutica, Inc., indicated that PHY906 was different from HQD currently available in the market owing to unique and defined procedures for preparation, standardized chemical fingerprints, and quality control (Tilton et al., 2010). 
Preclinical models and phase I/II clinical trials have shown that PHY906 exerted beneficial effects on outcomes of advanced liver, colorectal, and pancreatic cancers (Farrell and Kummar, 2003; Lam et al., 2010; Saif et al., 2014). Not only could PHY906 enhance therapeutic indices of a broad spectrum of anticancer drugs such as CPT-11, capecitabine, and sorafenib (Saif et al., 2014; Lam et al., 2015), but it also markedly alleviated toxicity caused by chemotherapeutic agents such as CPT-11 when co-administered with PHY906 (Saif et al., 2010; Lam et al., 2010). In a murine colon 38 allograft model, oral administration of PHY906 (50, 150, 500, or $1000 \mathrm{mg} / \mathrm{kg}$; b.i.d.) reduced CPT-11-induced GI toxicity in vivo through multiple modes of action, including attenuation of intestinal inflammation through inhibition of the NF- $k B$, COX-2, and iNOS inflammatory pathways, and promotion of intestinal progenitor cell repopulation by increasing expression of several Wnt signaling components and potentiating wnt3a action (Lam et al., 2010).

A phase I, multicenter, double-blind, randomized, placebocontrolled, crossover study of PHY906 in combination with CPT-11 and 5-FU/ Leucovrin (IFL) chemotherapy involving 17 patients with advanced colorectal cancer was conducted. PHY906 decreased the overall incidence of grade 3 or 4 diarrhea in patients and contributed to lower use of the antidiarrheal drugs loperamide and lomotil. In addition, PHY906 did not alter the pharmacokinetics of CPT-11, or the CPT-11 metabolite SN-38 (Kummar et al., 2011).

\section{Hange-shashin-to}

The Japanese Kampo medicine Hange-shashin-to is composed of seven herbs (Table 2) and has been used as an herbal formula to treat diarrhea and acute gastroenteritis (Kase et al., 1997b; Kawashima et al., 2004). In an animal experiment, Hangeshashin-to ( $1 \mathrm{~g} / \mathrm{kg}$; b.i.d.) and baicalin $(25 \mathrm{mg} / \mathrm{kg}$; b.i.d.), the primary flavonoid in Hange-shashin-to, exhibited protective effects against CPT-11-induced intestinal toxicity by inhibiting $\beta$-glucuronidase activity, resulting in decreased weight loss, improved anorexia, and delayed onset of diarrhea symptoms (Narita et al., 1993; Takasuna et al., 1995b).

Furthermore, repeated oral administrations of Hangeshashin-to at 125 or $500 \mathrm{mg} / \mathrm{kg}$ markedly suppressed chronic diarrheal symptoms due to CPT-11 in rats in a dose-dependent manner, which was mediated by decreasing production of colonic prostaglandin E2 (PGE2) and stimulating colonic water absorption (Kase et al., 1997a, 1998). Kase et al. (1998) revealed that three components of Hange-shashin-to, Scutellariae radix, Glycyrrhizae radix, and Coptidis rhizoma selectively inhibited cyclooxygenase-2 (COX-2) activity. Glycyrrhizin and glycyrrhetinic acid contained in Glycyrrhizae radix, and ginsenosides contained in Ginseng radix were reported to enhance colonic water absorption through promotion of corticosterone secretion.

Mori et al. (2003) from the Tochigi Cancer Center Research Group conducted a randomized comparative clinical trial involving 41 patients with non-small cell lung cancer treated with cisplatin and CPT-11. They reported that the Hangeshashin-to group ( $7.5 \mathrm{~g} / \mathrm{body}$; t.i.d.) showed markedly improved grades of diarrhea $(P=0.044)$ and reduced frequency of severe grade 3 or 4 diarrhea $(P=0.018)$ as compared to the control group.

\section{Sairei-to}

Sairei-to, a traditional Japanese herbal medicine used to treat severe diarrhea and various inflammatory diseases such as rheumatoid arthritis, systemic lupus erythematodes, and nephrotic syndrome, is made from a combined formulation of twelve medicinal herbs (Ito et al., 2002; Kato et al., 2015). In a preclinical study conducted on male Wistar rats, co-administration of Sairei-to $(1 \mathrm{~g} / \mathrm{kg}$; b.i.d.) alleviated CPT-11-induced delayed-onset diarrhea. The probable mechanism of action was related to the inhibition of bacterial $\beta$-glucuronidase (Takasuna et al., 1995b). Recently, Satoh et al. (2018) investigated the inhibitory effects of $\beta$-glucuronidasetreated or untreated Sairei-to on SN-38 glucuronidation in human liver microsomes. They reported that $\beta$-glucuronidasetreated Sairei-to remarkably increased baicalein, which was the key ingredient responsible for inhibition of UGT activity. Baicalein, the deglycosylation product of baicalin derived from Sairei-to, could be a pharmacokinetic regulating factor associated with SN-38-induced late-onset diarrhea in vitro. Similarly, Kato et al. (2015) demonstrated that Sairei-to (100, 300, or $1000 \mathrm{mg} / \mathrm{kg}$; b.i.d.) dose-dependently attenuated 5 -FU-induced diarrhea in mice during chemotherapy via suppression of up-regulation of inflammatory cytokines such as TNF- $\alpha$, IL-1 $\beta$, and TGF- $\beta$.

\section{Shengjiang Xiexin Decoction}

Shengjiang Xiexin decoction (SXD), a traditional Chinese medicine prescribed in Shang Han Lun, is composed of eight Chinese herbs (Table 2) and is widely used in modern clinical practice to treat gastroenteritis, ulcerative colitis, and diarrhea (Deng et al., 2017; Guan et al., 2017b; Peng et al., 2017). In a diarrhea rat model, $\operatorname{SXD}(5,10$, or $15 \mathrm{~g} / \mathrm{kg} /$ day) prevented CPT-11-induced delayed-onset diarrhea in a dose-dependent manner via inhibition of intestinal apoptosis and $\beta$-glucuronidase and promotion of intestinal cell proliferation (Deng et al., 2017). Using a sensitive and accurate UHPLC-MS/MS method, Guan et al. (2017a,b) demonstrated that the active constituents and metabolites derived from SXD (10 g/kg; b.i.d.) could synergistically alter the pharmacokinetics of CPT-11 to alleviate diarrhea. These alterations were associated with decreased hepatic expression of multidrug resistance-associated protein-2 (Mrp-2) and P-glycoprotein (P-gp), inhibition of CPT-11 hydrolysis to SN-38 by carboxylesterase, and improved glucuronidation of SN-38 to SN-38G. Glycyrrhizin and glycyrrhetinic acid, derived from SXD, are known inhibitors of Mrp-2 (Feng et al., 2015). The flavonoid oroxylin A, a product of metabolism of SXD by intestinal bacteria, has been reported to effectively inhibit P-gp expression (Go et al., 2009). Moreover, chrysin is likely responsible for conversion of $\mathrm{SN}-38$ to $\mathrm{SN}-38 \mathrm{G}$ in 
the gastrointestinal tract through up-regulation of UGT1A1 (Guan et al., 2017b).

A randomized controlled trial was performed by Deng et al. (2017) involving 115 patients who received CPT-11 combined with 5-fluorouracil plus l-leucovorin treatment. SXD (100 mL; b.i.d.) significantly reduced delayed-onset diarrhea in $\mathrm{UGT} 1 \mathrm{~A} 1 * 28$ or ${ }^{*} \mathrm{UGT} 1 \mathrm{~A} 1 * 6$ variant patients (high risk groups for CPT-11-induced hematological and GI toxicities) without affecting clinical response to chemotherapy (Deng et al., 2017).

\section{Banxia Xiexin Decoction}

Banxia Xiexin decoction (BXD) consists of seven herbs (Table 2) and is an effective Chinese medicine prescribed for treatment of gastroenteritis, ulcerative colitis, vomiting, and diarrhea (Tian et al., 2013; Wang X. et al., 2014; Wang Y. et al., 2014). Wang Y. et al. (2014) successfully used a validated UPLC-MS/MS method to accurately quantitate 18 bioactive compounds in BXD, including flavonoids, alkaloids, and saponins. Twenty-seven Chinese patients with recurrent small cell lung cancer receiving CPT-11 chemotherapy were enrolled into a clinical study performed by Lu et al. (2018). This study confirmed that BXD was effective in preventing and controlling CPT-11-induced delayed-onset diarrhea. Delayed-onset diarrhea occurred in six patients, and 4 of 5 patients that received BXD treatment experienced relief from diarrhea symptoms. However, the overall number of patients with delayed-onset diarrhea enrolled on to this trial was relatively small. As such, the efficacy of BXD in prevention and control of delayed-onset diarrhea caused by CPT-11 should be further evaluated in a high quality RCT with a larger sample size.

\section{St. John's Wort (Hypericum perforatum)}

St. John's wort (Hypericum perforatum) is one of the most commonly used herbal medicines for treatment of depression, hypertension, and inflammation (Di Carlo et al., 2001; Fiebich et al., 2001; Rahimi and Abdollahi, 2012). Over two dozen compounds were identified in St. John's wort, among which hyperforin, hypericin, and quercetin were the major active components (Hu et al., 2007). A preliminary study in a rat model clearly demonstrated that oral pretreatment with St. John's wort (400 $\mathrm{mg} / \mathrm{kg} / \mathrm{day})$ for 8 consecutive days significantly reduced both early- and late-onset diarrhea induced by use of CPT-11 (Hu et al., 2005, 2006). This protective effect was partially attributed to modulation of CPT11 and SN-38 pharmacokinetics by the main constituents of St. John's wort (Hu et al., 2005, 2007). Additionally, co-administration of St. John's wort and CPT-11 prevented intestinal histological damage and diarrhea via inhibition of intestinal epithelial apoptosis and pro-inflammatory cytokine expression in the intestine, including IFN- $\gamma$, IL-6, IL- $1 \beta$, and TNF- $\alpha$ (Hu et al., 2006). In an unblinded, randomized crossover study on 5 cancer patients, oral treatment with $900 \mathrm{mg} /$ day St. John's wort for 18 days attenuated CPT11-induced diarrhea by decreasing plasma levels of SN-38 (Mathijssen et al., 2002).

\section{Others}

The flavonoid-rich fraction (100 $\mathrm{mg} / \mathrm{kg} / \mathrm{day} ;$ p.o.) from Bauhinia forficata leaves, collected at Itajaí, Santa Catarina (Brazil), has been shown to partially mitigate intestinal mucositis in mice, which is characterized by diarrhea and histological damage without interfering with anticancer efficacy of CPT-11. Probable mechanisms were the maintenance of protective factors in the duodenum, the augmented viability of GSH, and the increased release of pro-inflammatory cytokines, particularly TNF- $\alpha$ (Cechinel-Zanchett et al., 2018). de Alencar et al. (2017) reported that latex proteins (1, 5, or $50 \mathrm{mg} / \mathrm{kg} /$ day; i.v.) from Calotropis procera prevented intestinal damage and persistent diarrhea in a dose-dependent manner in CPT-11-treated animals by down-regulating key proinflammatory mediators such as COX-2, TNF- $\alpha$, IL- $1 \beta$, iNOS, and NF- $\mathrm{NB}$.

Hesperetin, a widely distributed flavonoid in many plant fruits and flowers, and foods of plant origin, has been reported to have powerful antioxidant, cholesterollowering, and anti-inflammatory pharmacological properties (Parhiz et al., 2015; Polat et al., 2018). Oral administration of hesperetin (20 or $100 \mathrm{mg} / \mathrm{kg} /$ day) exerted a remarkable anti-diarrhea effect, blocking $80 \%$ of severe and $100 \%$ of mild diarrhea cases observed in mice given CPT-11. The mechanism of action of hesperetin was attenuation of intestinal damage caused by $\mathrm{SN}-38$ accumulation via selective inhibition of intestinal carboxylesterase (Yu et al., 2018).

\section{CONCLUSION AND FUTURE PROSPECTS}

CPT-11 is a potent anticancer agent for the treatment of colorectal, non-small cell lung cancer, and various other cancers and has been used for almost two decades. However, severe and persistent diarrhea greatly compromise the efficacy and safety of CPT-11-based chemotherapy. Although effective therapies for acute diarrhea resulting from enhanced intestinal motility caused by the inhibition of cholinesterase are available, there are no effective treatments and/or prevention strategies for CPT-11induced delayed-onset diarrhea.

As shown in this review, preclinical and clinical studies have indicated that several herbal formulations, medicine preparations, plant extracts, and phytoconstituents have potential to prevent or attenuate chronic diarrheal symptoms during CPT-11-based chemotherapy. The proposed mechanisms of action of herbal medicines for treatment of delayed-onset diarrhea are diverse, mainly acting on metabolism of CPT11, which occurs through a number of enzymes, metabolites, and transporters.

Herbal prescriptions are often composed of more than one herb, and chemical components within a single herb can be complex and varied. Further investigations should focus on characterization of bioactive compounds responsible for the 
protective effects against CPT-11-induced diarrhea and indepth studies of mechanisms of action. Although some progress has been made in basic research and clinical application of herbal medicines for treatment of CPT-11-related diarrhea, many clinical trials were not well-designed with small sample sizes, poor methodological control, and short durations of therapy and follow-up. Larger methodologically sound, randomized controlled trials should be performed in the future.

\section{REFERENCES}

Abigerges, D., Armand, J. P., Chabot, G. G., Da, C. L., Fadel, E., Cote, C., et al. (1994). Irinotecan (CPT-11) high-dose escalation using intensive high-dose loperamide to control diarrhea. J. Natl. Cancer. Inst. 86, 446-449. doi: 10.1093/ jnci/86.6.446

Ahmed, F., Vyas, V., Cornfield, A., Goodin, S., Ravikumar, T. S., Rubin, E. H., et al. (1999). In vitro activation of irinotecan to SN-38 by human liver and intestine. Anticancer Res. 19, 2067-2071.

Andreyev, J., Ross, P., Donnellan, C., Lennan, E., Leonard, P., Waters, C., et al. (2014). Guidance on the management of diarrhoea during cancer chemotherapy. Lancet Oncol. 15, e447-e460. doi: 10.1016/S1470-2045(14) 70006-3

Arbuckle, R. B., Huber, S. L., and Zacker, C. (2000). The consequences of diarrhea occurring during chemotherapy for colorectal cancer: a retrospective study. Oncologist 5, 250-259. doi: 10.1634/theoncologist.5-3-250

Arnold, R. J., Gabrail, N., Raut, M., Kim, R., Sung, J. C., and Zhou, Y. (2005). Clinical implications of chemotherapy-induced diarrhea in patients with cancer. J. Support. Oncol. 3, 227-232.

Barbounis, V., Koumakis, G., Vassilomanolakis, M., Demiri, M., and Efremidis, A. P. (2001). Control of irinotecan-induced diarrhea by octreotide after loperamide failure. Support. Care Cancer 9, 258-260. doi: $10.1007 /$ s005200000220

Bensky, D., and Barolet, R. (1990). Chinese Herbal Medicine: Formulas and Strategies. Seattle: Eastland Press.

Benson, A. R., Ajani, J. A., Catalano, R. B., Engelking, C., Kornblau, S. M., Martenson, J. J., et al. (2004). Recommended guidelines for the treatment of cancer treatment-induced diarrhea. J. Clin. Oncol. 22, 2918-2926. doi: 10.1200/ JCO.2004.04.132

Benyamin, R., Trescot, A. M., Datta, S., Buenaventura, R., Adlaka, R., Sehgal, N., et al. (2008). Opioid complications and side effects. Pain Physician 11, S105S120.

Bleiberg, H., and Cvitkovic, E. (1996). Characterisation and clinical management of CPT-11 (irinotecan)-induced adverse events: the European perspective. Eur. J. Cancer 32A(Suppl. 3), S18-S23. doi: 10.1016/0959-8049(96)00293-6

Cechinel-Zanchett, C. C., Boeing, T., Somensi, L. B., Steimbach, V., Campos, A., Krueger, C., et al. (2018). Flavonoid-rich fraction of Bauhinia forficata link leaves prevents the intestinal toxic effects of irinotecan chemotherapy in IEC-6 cells and in mice. Phytother. Res. 33, 90-106. doi: 10.1002/ptr.6202

Chen, G., Yang, Y., Liu, M., Teng, Z., Ye, J., Xu, Y., et al. (2015). Banxia xiexin decoction protects against dextran sulfate sodium-induced chronic ulcerative colitis in mice. J. Ethnopharmacol. 166, 149-156. doi: 10.1016/j.jep.2015.03.027

Cui, D. N., Wang, X., Chen, J. Q., Lv, B., Zhang, P., Zhang, W., et al. (2017). Quantitative evaluation of the compatibility effects of huangqin decoction on the treatment of irinotecan-induced gastrointestinal toxicity using untargeted metabolomics. Front. Pharmacol. 8:211. doi: 10.3389/fphar.2017.00211

de Alencar, N. M., Da, S. B. F., de Figueiredo, I. S., Luz, P. B., Lima-Junior, R. C., Aragao, K. S., et al. (2017). Side-effects of irinotecan (CPT-11), the clinically used drug for colon cancer therapy, are eliminated in experimental animals treated with latex proteins from Calotropis procera (Apocynaceae). Phytother. Res. 31, 312-320. doi: 10.1002/ptr.5752

Deng, B., Jia, L., Tan, H., Lou, Y., Li, X., Li, Y., et al. (2017). Effects of shengjiangxiexin decoction on irinotecan-induced toxicity in patients with UGT1A1*28 and UGT1A1*6 polymorphisms. J. Tradit. Chin. Med. 37, 35-42. doi: 10.1016/S0254-6272(17)30024-9

\section{AUTHOR CONTRIBUTIONS}

All listed authors fulfill the requirements for authorship and have approved the final version of the manuscript. LT and HD prepared the manuscript. HD conceived the idea, reviewed the drafts, and provided important information for the completion of this manuscript. XL, LW, YX, and XZ contributed to the revision of the manuscript.

Di Carlo, G., Borrelli, F., Ernst, E., and Izzo, A. A. (2001). St John's wort: prozac from the plant kingdom. Trends Pharmacol. Sci. 22, 292-297. doi: 10.1016/ S0165-6147(00)01716-8

Dranitsaris, G., Maroun, J., and Shah, A. (2005). Estimating the cost of illness in colorectal cancer patients who were hospitalized for severe chemotherapyinduced diarrhea. Can. J. Gastroenterol. 19, 83-87. doi: 10.1155/2005/618504

Farrell, M. P., and Kummar, S. (2003). Phase I/IIA randomized study of PHY906, a novel herbal agent, as a modulator of chemotherapy in patients with advanced colorectal cancer. Clin. Colorectal. Cancer 2, 253-256. doi: 10.3816/CCC.2003. n.007

Feng, X., Ding, L., and Qiu, F. (2015). Potential drug interactions associated with glycyrrhizin and glycyrrhetinic acid. Drug Metab. Rev. 47, 229-238. doi: 10. 3109/03602532.2015.1029634

Fiebich, B. L., Hollig, A., and Lieb, K. (2001). Inhibition of substance P-induced cytokine synthesis by St. John's wort extracts. Pharmacopsychiatry 34(Suppl. 1), S26-S28.

Gandia, D., Abigerges, D., Armand, J. P., Chabot, G., Da, C. L., De Forni, M., et al. (1993). CPT-11-induced cholinergic effects in cancer patients. J. Clin. Oncol. 11, 196-197. doi: 10.1200/JCO.1993.11.1.196

Gebbia, V., Carreca, I., Testa, A., Valenza, R., Curto, G., Cannata, G., et al. (1993). Subcutaneous octreotide versus oral loperamide in the treatment of diarrhea following chemotherapy. Anticancer Drugs 4, 443-445. doi: 10.1097/00001813199308000-00004

Go, W. J., Ryu, J. H., Qiang, F., and Han, H.-K. (2009). Evaluation of the flavonoid oroxylin A as an inhibitor of P-glycoprotein-mediated cellular efflux. J. Nat. Prod. 72, 1616-1619. doi: 10.1021/np9003036

Guan, H. Y., Li, P. F., Wang, X. M., Yue, J. J., He, Y., Luo, X. M., et al. (2017a). Shengjiang xiexin decoction alters pharmacokinetics of irinotecan by regulating metabolic enzymes and transporters: a multi-target therapy for alleviating the gastrointestinal toxicity. Front. Pharmacol. 8:769. doi: 10.3389/fphar.2017. 00769

Guan, H. Y., Wang, X. M., Wang, S. P., He, Y., Yue, J. J., Liao, S. G., et al. (2017b). Comparative intestinal bacteria-associated pharmacokinetics of 16 components of Shengjiang Xiexin decoction between normal rats and rats with irinotecan hydrochloride (CPT-11)-induced gastrointestinal toxicity in vitro using saltingout sample preparation and LC-MS/MS. RSC Adv. 7, 43621-43635. doi: 10. 1039/C7RA03521G

Hayashi, H., Tsurutani, J., Satoh, T., Masuda, N., Okamoto, W., Morinaga, R., et al. (2013). Phase II study of bi-weekly irinotecan for patients with previously treated HER2-negative metastatic breast cancer: KMBOG0610B. Breast Cancer 20, 131-136. doi: 10.1007/s12282-011-0316-z

Hecht, J. R. (1998). Gastrointestinal toxicity or irinotecan. Oncology 12, 72-78.

Hoff, P. M., Saragiotto, D. F., Barrios, C. H., Del, G. A., Coutinho, A. K., Andrade, A. C., et al. (2014). Randomized phase III trial exploring the use of long-acting release octreotide in the prevention of chemotherapy-induced diarrhea in patients with colorectal cancer: the LARCID trial. J. Clin. Oncol. 32, 1006-1011. doi: 10.1200/JCO.2013.50.8077

Hori, S., Mihaylov, I., Vasconcelos, J. C., and McCoubrie, M. (2008). Patterns of complementary and alternative medicine use amongst outpatients in Tokyo, Japan. BMC Complement. Altern. Med. 8:14. doi: 10.1186/1472-6882-8-14

Hu, Z. P., Yang, X. X., Chan, S. Y., Xu, A. L., Duan, W., Zhu, Y. Z., et al. (2006). St. John's wort attenuates irinotecan-induced diarrhea via down-regulation of intestinal pro-inflammatory cytokines and inhibition of intestinal epithelial apoptosis. Toxicol. Appl. Pharmacol. 216, 225-237. doi: 10.1016/j.taap.2006. 05.020 
Hu, Z. P., Yang, X. X., Chen, X., Cao, J., Chan, E., Duan, W., et al. (2007). A mechanistic study on altered pharmacokinetics of irinotecan by St. John's wort. Curr. Drug Metab. 8, 157-171. doi: 10.2174/138920007779815995

Hu, Z. P., Yang, X. X., Ho, P. C., Chan, E., Chan, S. Y., Xu, C. J., et al. (2005). St. John's Wort modulates the toxicities and pharmacokinetics of CPT-11 (irinotecan) in rats. Pharm. Res. 22, 902-914. doi: 10.1007/s11095-005-4585-0

Ito, T., Seo, N., Yagi, H., Ohtani, T., Tokura, Y., Takigawa, M., et al. (2002). Unique therapeutic effects of the Japanese-Chinese herbal medicine, saireito, on Th1/Th2 cytokines balance of the autoimmunity of MRL/lpr mice. J. Dermatol. Sci. 28, 198-210. doi: 10.1016/S0923-1811(01)00161-X

Kakolyris, S., Souglakos, J., Kouroussis, C., Androulakis, N., Mavroudis, D., Kalbakis, K., et al. (2001). A dose-finding study of irinotecan (CPT-11) plus a four-day continuous 5-fluorouracil infusion in advanced colorectal cancer. Oncology 60, 207-213. doi: 10.1159/000055320

Kase, Y., Hayakawa, T., Aburada, M., Komatsu, Y., and Kamataki, T. (1997a). Preventive effects of Hange-shashin-to on irinotecan hydrochloride-caused diarrhea and its relevance to the colonic prostaglandin E2 and water absorption in the rat. Jpn. J. Pharmacol. 75, 407-413.

Kase, Y., Hayakawa, T., Ishige, A., Aburada, M., and Komatsu, Y. (1997b). The effects of Hange-shashin-to on the content of prostaglandin E2 and water absorption in the large intestine of rats. Biol. Pharm. Bull. 20, 954-957.

Kase, Y., Saitoh, K., Ishige, A., and Komatsu, Y. (1998). Mechanisms by which hange-shashin-to reduces prostaglandin E2 levels. Biol. Pharm. Bull. 21, 12771281. doi: 10.1248/bpb.21.1277

Kato, S., Hayashi, S., Kitahara, Y., Nagasawa, K., Aono, H., Shibata, J., et al. (2015). Saireito (TJ-114), a Japanese traditional herbal medicine, reduces 5-fluorouracil-induced intestinal mucositis in mice by inhibiting cytokinemediated apoptosis in intestinal crypt cells. PLoS One 10:e116213. doi: 10.1371/ journal.pone.0116213

Kawashima, K., Nomura, A., Makino, T., Saito, K., and Kano, Y. (2004). Pharmacological properties of traditional medicine (XXIX): effect of hangeshashin-to and the combinations of its herbal constituents on rat experimental colitis. Biol. Pharm. Bull. 27, 1599-1603. doi: 10.1248/bpb.27.1599

Kehrer, D. F., Sparreboom, A., Verweij, J., de Bruijn, P., Nierop, C. A., van de Schraaf, J., et al. (2001). Modulation of irinotecan-induced diarrhea by cotreatment with neomycin in cancer patients. Clin. Cancer Res. 7, 1136-1141.

Kummar, S., Copur, M. S., Rose, M., Wadler, S., Stephenson, J., O’Rourke, M., et al. (2011). A phase I study of the chinese herbal medicine PHY906 as a modulator of irinotecan-based chemotherapy in patients with advanced colorectal cancer. Clin. Colorectal Cancer 10, 85-96. doi: 10.1016/j.clcc.2011. 03.003

Lam, W., Bussom, S., Guan, F., Jiang, Z., Zhang, W., Gullen, E. A., et al. (2010). The four-herb Chinese medicine PHY906 reduces chemotherapy-induced gastrointestinal toxicity. Sci. Transl. Med. 2, 45r-59r. doi: 10.1126/scitranslmed. 3001270

Lam, W., Jiang, Z., Guan, F., Huang, X., Hu, R., Wang, J., et al. (2015). PHY906(KD018), an adjuvant based on a 1800-year-old Chinese medicine, enhanced the anti-tumor activity of Sorafenib by changing the tumor microenvironment. Sci. Rep. 5:9384. doi: 10.1038/srep09384

Liu, S. H., and Cheng, Y. C. (2012). Old formula, new Rx: the journey of PHY906 as cancer adjuvant therapy. J. Ethnopharmacol. 140, 614-623. doi: 10.1016/j.jep. 2012.01.047

Logan, R. M., Gibson, R. J., Bowen, J. M., Stringer, A. M., Sonis, S. T., and Keefe, D. M. (2008). Characterisation of mucosal changes in the alimentary tract following administration of irinotecan: implications for the pathobiology of mucositis. Cancer Chemother. Pharmacol. 62, 33-41. doi: 10.1007/s00280-0070570-0

Lu, H., Qin, J., Han, N., Xie, F., Gong, L., Li, C., et al. (2018). Banxia xiexin decoction is effective to prevent and control irinotecan-induced delayed diarrhea in recurrent small cell lung cancer. Integr. Cancer Ther. 17, 1109-1114. doi: $10.1177 / 1534735418801532$

Mathijssen, R. H., Verweij, J., de Bruijn, P., Loos, W. J., and Sparreboom, A. (2002). Effects of St. John's wort on irinotecan metabolism. J. Natl. Cancer Inst. 94, 1247-1249. doi: 10.1093/jnci/94.16.1247

McQuade, R. M., Stojanovska, V., Abalo, R., Bornstein, J. C., and Nurgali, K. (2016). Chemotherapy-induced constipation and diarrhea: pathophysiology, current and emerging treatments. Front. Pharmacol. 7:414. doi: 10.3389/fphar.2016. 00414
Melo, M. L., Brito, G. A., Soares, R. C., Carvalho, S. B., Silva, J. V., Soares, P. M., et al. (2008). Role of cytokines (TNF-alpha, IL-1beta and KC) in the pathogenesis of CPT-11-induced intestinal mucositis in mice: effect of pentoxifylline and thalidomide. Cancer Chemother. Pharmacol. 61, 775-784. doi: 10.1007/s00280-007-0534-4

Mori, K., Kondo, T., Kamiyama, Y., Kano, Y., and Tominaga, K. (2003). Preventive effect of Kampo medicine (Hangeshashin-to) against irinotecaninduced diarrhea in advanced non-small-cell lung cancer. Cancer Chemother. Pharmacol. 51, 403-406.

Mukai, M., Okada, K., Fukumitsu, H., Yazawa, N., Hoshikawa, T., Tajima, T., et al. (2009). Efficacy of 5-FU/LV plus CPT-11 as first-line adjuvant chemotherapy for stage IIIa colorectal cancer. Oncol. Rep. 22, 621-629. doi: 10.3892/or_000 00481

Narita, M., Nagai, E., Hagiwara, H., Aburada, M., Yokoi, T., and Kamataki, T. (1993). Inhibition of beta-glucuronidase by natural glucuronides of kampo medicines using glucuronide of SN-38 (7-ethyl-10-hydroxycamptothecin) as a substrate. Xenobiotica 23, 5-10. doi: 10.3109/00498259309059356

Parhiz, H., Roohbakhsh, A., Soltani, F., Rezaee, R., and Iranshahi, M. (2015). Antioxidant and anti-inflammatory properties of the citrus flavonoids hesperidin and hesperetin: an updated review of their molecular mechanisms and experimental models. Phytother. Res. 29, 323-331. doi: 10.1002/ptr. 5256

Park, H. L., Lee, H. S., Shin, B. C., Liu, J. P., Shang, Q., Yamashita, H., et al. (2012). Traditional medicine in china, Korea, and Japan: a brief introduction and comparison. Evid. Based Complement. Alternat. Med. 2012:429103. doi: $10.1155 / 2012 / 429103$

Peng, G., Guan, H., Wang, X., and Shi, Y. (2017). Simultaneous determination of 14 active constituents of Shengjiang Xiexin decoction using ultrafast liquid chromatography coupled with electrospray ionization tandem mass spectrometry. Acta Pharm. Sin. B 7, 193-201. doi: 10.1016/j.apsb. 2016.11.006

Polat, F. R., Karaboga, I., Polat, M. S., Erboga, Z., Yilmaz, A., and Guzel, S. (2018). Effect of hesperetin on inflammatory and oxidative status in trinitrobenzene sulfonic acid-induced experimental colitis model. Cell Mol. Biol. 64, 58-65. doi: $10.14715 / \mathrm{cmb} / 2018.64 .11 .11$

Rahimi, R., and Abdollahi, M. (2012). An update on the ability of St. John's wort to affect the metabolism of other drugs. Expert Opin. Drug Metab. Toxicol. 8, 691-708. doi: 10.1517/17425255.2012.680886

Rashrash, M., Schommer, J. C., and Brown, L. M. (2017). Prevalence and predictors of herbal medicine use among adults in the United States. J. Patient Exp. 4, 108-113. doi: 10.1177/2374373517706612

Richardson, G., and Dobish, R. (2007). Chemotherapy induced diarrhea. J. Oncol. Pharm. Pract. 13, 181-198. doi: 10.1177/107815520707 7335

Rosen, L. S. (1998). Irinotecan in lymphoma, leukemia, and breast, pancreatic, ovarian, and small-cell lung cancers. Oncology 12, 103-109.

Rothenberg, M. L., Meropol, N. J., Poplin, E. A., Van Cutsem, E., and Wadler, S. (2001). Mortality associated with irinotecan plus bolus fluorouracil/leucovorin: summary findings of an independent panel. J. Clin. Oncol. 19, 3801-3807. doi: 10.1200/JCO.2001.19.18.3801

Saif, M. W., Lansigan, F., Ruta, S., Lamb, L., Mezes, M., Elligers, K., et al. (2010). Phase I study of the botanical formulation PHY906 with capecitabine in advanced pancreatic and other gastrointestinal malignancies. Phytomedicine 17, 161-169. doi: 10.1016/j.phymed.2009.12.016

Saif, M. W., Li, J., Lamb, L., Kaley, K., Elligers, K., Jiang, Z., et al. (2014). First-in-human phase II trial of the botanical formulation PHY906 with capecitabine as second-line therapy in patients with advanced pancreatic cancer. Cancer Chemother. Pharmacol. 73, 373-380. doi: 10.1007/s00280-0132359-7

Satoh, T., Igarashi, A., Tanno, M., Yamada, K., Takahashi-Suzuki, N., and Watanabe, K. (2018). Inhibitory effects of baicalein derived from japanese traditional herbal medicine on SN-38 glucuronidation. J. Pharm. Pharm. Sci. 21, 195-206. doi: 10.18433/jpps29783

Satouchi, M., Kotani, Y., Shibata, T., Ando, M., Nakagawa, K., Yamamoto, N., et al. (2014). Phase III study comparing amrubicin plus cisplatin with irinotecan plus cisplatin in the treatment of extensive-disease small-cell lung cancer: JCOG 0509. J. Clin. Oncol. 32, 1262-1268. doi: 10.1200/JCO.2013.53. 5153 
Sharma, R., Tobin, P., and Clarke, S. J. (2005). Management of chemotherapyinduced nausea, vomiting, oral mucositis, and diarrhoea. Lancet Oncol. 6, 93-102. doi: 10.1016/S1470-2045(05)01735-3

Smith, N. F., Figg, W. D., and Sparreboom, A. (2006). Pharmacogenetics of irinotecan metabolism and transport: an update. Toxicol. In Vitro 20, 163-175. doi: 10.1016/j.tiv.2005.06.045

Stein, A., Voigt, W., and Jordan, K. (2010). Chemotherapy-induced diarrhea: pathophysiology, frequency and guideline-based management. Ther. Adv. Med. Oncol. 2, 51-63. doi: 10.1177/1758834009355164

Swami, U., Goel, S., and Mani, S. (2013). Therapeutic targeting of CPT-11 induced diarrhea: a case for prophylaxis. Curr. Drug Targets 14, 777-797. doi: 10.2174/ 1389450111314070007

Takasuna, K., Kasai, Y., Kitano, Y., Mori, K., Kakihata, K., Hirohashi, M., et al. (1995a). Study on the mechanisms of diarrhea induced by a new anticancer camptothecin derivative, irinotecan hydrochloride (CPT-11), in rats. Nihon Yakurigaku Zasshi 105, 447-460.

Takasuna, K., Kasai, Y., Kitano, Y., Mori, K., Kobayashi, R., Hagiwara, T., et al. (1995b). Protective effects of kampo medicines and baicalin against intestinal toxicity of a new anticancer camptothecin derivative, irinotecan hydrochloride (CPT-11), in rats. Jpn. J. Cancer Res. 86, 978-984.

Tang, W., and Eisenbrand, G. (1992). Chinese Drugs of Plant Origin: Chemistry, Pharmacology and Use in Traditional and Modern Medicine, 1st Edn. New York, NY: Springer-Verlag Press. doi: 10.1007/978-3-642-73739-8

Tian, J., Li, M., Liao, J., Li, J., and Tong, X. (2013). Chinese herbal medicine banxiaxiexin decoction treating diabetic gastroparesis: a systematic review of randomized controlled trials. Evid. Based Complement. Alternat. Med. 2013, 749495. doi: 10.1155/2013/749495

Tilton, R., Paiva, A. A., Guan, J. Q., Marathe, R., Jiang, Z., van Eyndhoven, W., et al. (2010). A comprehensive platform for quality control of botanical drugs (PhytomicsQC): a case study of Huangqin Tang (HQT) and PHY906. Chin. Med. 5:30. doi: 10.1186/1749-8546-5-30

Wang, J., Fan, H., Wang, Y., Wang, X., Zhang, P., Chen, J., et al. (2015). Metabolomic study of Chinese medicine Huang Qin decoction as an effective treatment for irinotecan-induced gastrointestinal toxicity. RSC Adv. 5, 2642026429. doi: 10.3389/fphar.2017.00211

Wang, X., Cui, D. N., Dai, X. M., Wang, J., Zhang, W., Zhang, Z. J., et al. (2017). HuangQin decoction attenuates CPT-11-induced gastrointestinal toxicity by regulating bile acids metabolism homeostasis. Front. Pharmacol. 8:156. doi: 10.3389/fphar.2017.00156

Wang, X., Yang, J., Cao, Q., and Tang, J. (2014). Therapeutic efficacy and mechanism of water-soluble extracts of Banxiaxiexin decoction on BALB/c mice with oxazolone-induced colitis. Exp. Ther. Med. 8, 1201-1204. doi: 10.3892/ etm.2014.1890

Wang, Y., Xu, R., Xiao, J., Zhang, J., Wang, X., An, R., et al. (2014). Quantitative analysis of flavonoids, alkaloids and saponins of Banxia Xiexin decoction using ultra-high performance liquid chromatography coupled with electrospray ionization tandem mass spectrometry. J. Pharm. Biomed. Anal. 88, 525-535. doi: 10.1016/j.jpba.2013.10.002

Wang, Y., Fan, X., Qu, H., Gao, X., and Cheng, Y. (2012). Strategies and techniques for multi-component drug design from medicinal herbs and traditional Chinese medicine. Curr. Top. Med. Chem. 12, 1356-1362. doi: 10. 2174/156802612801319034

Yamakawa, J., Motoo, Y., Moriya, J., Ogawa, M., Uenishi, H., Akazawa, S., et al. (2013). Significance of Kampo, traditional Japanese medicine, in supportive care of cancer patients. Evid. Based Complement. Alternat. Med. 2013:746486. doi: $10.1155 / 2013 / 746486$

Yamashita, H., Tsukayama, H., and Sugishita, C. (2002). Popularity of complementary and alternative medicine in Japan: a telephone survey. Complement. Ther. Med. 10, 84-93. doi: 10.1054/ctim.2002. 0519

Yang, X., Hu, Z., Chan, S. Y., Chan, E., Goh, B. C., Duan, W., et al. (2005). Novel agents that potentially inhibit irinotecan-induced diarrhea. Curr. Med. Chem. 12, 1343-1358. doi: 10.2174/0929867054020972

Yokoi, T., Narita, M., Nagai, E., Hagiwara, H., Aburada, M., and Kamataki, T. (1995). Inhibition of UDP-glucuronosyltransferase by aglycons of natural glucuronides in kampo medicines using SN-38 as a substrate. Jpn. J. Cancer Res. 86, 985-989. doi: 10.1111/j.1349-7006.1995.tb03011.x

Yu, Y., Kong, R., Cao, H., Yin, Z., Liu, J., Nan, X., et al. (2018). Two birds, one stone: hesperetin alleviates chemotherapy-induced diarrhea and potentiates tumor inhibition. Oncotarget 9, 27958-27973. doi: 10.18632/oncotarget. 24563

Conflict of Interest Statement: The authors declare that the research was conducted in the absence of any commercial or financial relationships that could be construed as a potential conflict of interest.

Copyright (c) 2019 Tang, Li, Wan, Xiao, Zeng and Ding. This is an open-access article distributed under the terms of the Creative Commons Attribution License (CC BY). The use, distribution or reproduction in other forums is permitted, provided the original author(s) and the copyright owner(s) are credited and that the original publication in this journal is cited, in accordance with accepted academic practice. No use, distribution or reproduction is permitted which does not comply with these terms. 